\title{
Water and suspended sediments tracing to study hydrosedimentary transfers in a drained context : from the field to the catchment scale.
}

\author{
ARTHUR GAILLOT ${ }^{1,2}$, OLIVIER CERDAN ${ }^{2}$, CÉLESTINE \\ DELBART $^{1}$, PIERRE VANHOOYDONCK ${ }^{1}$, MARC \\ DESMET $^{3}$ AND SÉBASTIEN SALVADOR-BLANES ${ }^{1}$ \\ ${ }^{1}$ University of Tours, EA 6293 GéHCO \\ ${ }^{2}$ Bureau de Recherches Géologiques et Minières \\ ${ }^{3}$ University of Tours \\ Presenting Author: arthur.gaillot@univ-tours.fr
}

Agricultural productivity of humid plains has been increased thanks to the widespread implementation of surface and subsurface drainage. These two types of drainage systems increase dissolved and solid transfers from agricultural field to receiving environments and they are likely to modify the hydrological functioning of the drained fields and catchments. Several studies have shown the impact of subsurface drainage on water regime, notably, concerning a diminution of flow peak. Drainage created a new pathway for water and so for suspended solids. Less effort was devoted to investigate the impact on the erosion dynamics and very few studies were designed at the catchment scale. However, the comprehension of water and suspended solids dynamics from field to catchment outlet is a key to target adapted and efficient conservation measures to reduce erosion. We propose to trace both water and suspended solids to determine what the each way (surface vs. subsurface drainage) relative contributions to erosion are. Tracing water indicates the pathway and trancing suspended solids shows the source (soil surface vs. deeper soil). The study site is composed of a 196 ha agricultural catchment and a 5 ha field. The catchment is representative of the French agricultural intensive openfield catchments. Quantification of suspended solids and water fluxes (surface and subsurface) are monitored at high temporal resolution both at the field and catchment scales: since January 2019 at field scale and since September 2013 at catchment scale. Since November 2019, we trace the water flow (rain, soil water, subsurface flow and overland flow) using stables isotopes. Suspended solids are studied through their primary particle size and traced with radioactive isotopes. At the field scale, the quantification of hydric flows shows that surface drainage and subsurface drainage evacuate respectively $26 \%$ and $19 \%$ of the annual cumulated effective rainfall. Water tracing shows the existence of preferential flows in low water content soil as in water-saturated soil. At the catchment scale, water tracing shows that during a runoff event, surface runoff contributions are higher than subsurface runoff contribution. Suspended sediment tracing suggest suspended solids exported by surface and subsurface drainage have the same origin. 